\title{
ON CERTAIN CONSEQUENCES OF FEATURE SPREAD IN PHASE-BASED SYNTAX ${ }^{1}$
}

\author{
JACEK WITKOŚ \\ Adam Mickiewicz University, Poznań \\ wjacek@ifa.amu.edu.pl \\ PIOTR CEGŁOWSKI \\ Adam Mickiewicz University, Poznań \\ cpiotr@ifa.amu.edu.pl
}

\begin{abstract}
The paper presents some empirical consequences resulting from the application of Chomsky's phase-based system (Chomsky 2005, 2006) and, specifically, the implementation of feature spread between phase heads $(\mathrm{C}, \mathrm{v})$ and their complements $(\mathrm{T}, \mathrm{V})$, respectively. We begin with a brief overview of the "old" rules for the syntactic derivation and proceed with the description of the innovative concept of feature spread and the way it modifies the derivational process. Next, we hint at some problematic areas for the new system, i.e. extraction from the subject as well as that trace phenomenon. As for the former, we present, based on the comparison of the behaviour of raising as well as control verbs (including, among others, raising and control constructions), some evidence for the theory of Control as movement. What follows, we derive a parametrised version of Subject Condition. Finally, we look at certain facts from Polish (e.g. Genitive of Negation) that seem to lend credibility to the feature spread analysis.
\end{abstract}

KEYWORDS: Feature spread; subject extraction; phase-based derivation; Multiple Agree; Thattrace Effect.

\section{Introduction}

Chomsky $(2005,2006)$ presents a new approach to the minimalist procedure of feature checking/valuation. The chief idea is that only heads of projections which are derivational phases should be able to act as Probes in the Probe/Goal relationship mentioned above. $^{2}$

\footnotetext{
${ }^{1}$ We are grateful to an anonymous reviewer for critical assessment and a number of inspiring comments.

${ }^{2}$ Chomsky (2005: 10): "If only phase heads trigger operations (as I will assume), then IM will satisfy EM only for phase heads; apparent exceptions, such as raising to [spec,T], are derivative, via inheritance".
} 
The aim of this brief paper is to present the outline of Chomsky's $(2005,2006)$ system and to discuss some of its consequences for minimalist theorising. Some of these consequences turn out to be extremely useful and innovative, while others seem to clash with established (minimalist) ideas.

1. The gist of the new system of feature checking

One problem concerns extraction out of a DP argument. Apparently, the system presented in Chomsky $(2005,2006)$ allows for extraction out of an argument DP (deep search) only when:

(1a) the DP is placed at the non-head position of its A-chain (anti-freezing effect); ${ }^{3}$ (1b) the PIC is respected.

The PIC is a powerful condition regulating the mechanics of the derivation in narrow syntax:

(2) Phase Impenetrability Condition (Chomsky 1999: 10)

The domain of $\mathrm{H}$ is not accessible to operations at $\mathrm{ZP}$, but only $\mathrm{H}$ and its edge. (where: ZP is the least strong phase and the edge consists of specifiers)

Crucially, in the new system $\mathrm{T}$ is not an independent probe but inherits the [+EPP] and $[+\varphi]$ features from $C$ by the process of feature spread, which is said to apply in narrow syntax. ${ }^{4}$ Only $\mathrm{T}$ selected by $\mathrm{C}$ is able to check Nominative case, other types of $\mathrm{T}$ are 'defective' in that they can be only equipped with the [+EPP] feature, still somewhat mysterious, but they otherwise cannot value any nominal Goals. Consider examples relevant for Chomsky's discussion of the role of $\mathrm{C}$ and $\mathrm{T}$ in the derivation, and specifically of the process of "deep probing"; the accessing of a Goal embedded within an argument DP (subject or object). ${ }^{5}$

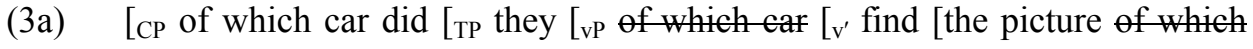
ear]]]]]

\footnotetext{
${ }^{3}$ In his earlier work Chomsky frequently said that the DP placed at the head of its A-chain is 'frozen in place', i.e. no longer visible and accessible to computation, as its formal features have been checked off.

${ }^{4}$ Chomsky (2005:9): “[...] for T, $\varphi$-features and Tense appear to be derivative from C. In the lexicon T lacks these features. T manifests them if and only if it is selected by $\mathrm{C}$ (default agreement aside); if not, it is a raising (or ECM) infinitival, lacking $\varphi$-features and tense. So it makes sense that Agree- and Tense-features are inherited from $\mathrm{C}$, the phase head".

${ }^{5}$ We follow the convention whereby copies left behind by movement processes are marked by a strikethrough. We also use traces $(t)$ where the copy convention is not required for the current discussion.
} 
(3b) $*\left[{ }_{\mathrm{CP}}\right.$ of which car did [ ${ }_{\mathrm{TP}}$ the picture of which car ${ }_{\mathrm{vP}}$ the picture of which car cause a scandal]]]

(3c) [ $[\mathrm{CP}$ of which car was [ $\mathrm{TP}$ the picture of which ear [vр awarded the pieture of which car a prize]]]

(3d) [CР of which car is [тр the picture of which car likely [TP the picture of which ear to [vp the picture of which car cause a scandal]]]]

The comparison of these examples leads to the formulation of the conditions in (1). Only the object position seems transparent to deep search/probing and extraction from within. ${ }^{6}$ Chomsky, however, does not discuss the issue of the extraction from one object with double object verbs. ${ }^{7}$ The thematic position of the subject (probably only in English-type languages) is never accessible to deep search. ${ }^{8}$ The top position in an A-chain turns the DP into an opaque domain for movement. ${ }^{9}$ We propose to call this effect the "freezing effect". The only opportunity to extract from within the subject DP appears when it is placed in an intermediate position within its A-chain. ${ }^{10}$

${ }^{6}$ Chomsky (2005: 13): "T is not the probe that yields A-movement of [the (driver, picture) of which] to the [spec, $\mathrm{T}]$ position before $\mathrm{C}$ is merged: if it were, the required distinction would again be effaced before whmovement. Rather, A-as well as A'-movement must be triggered by probes in $\mathrm{C}$ : the probe for $w h$-accesses which in its base position in (2c), raising of which to [spec,C], while the Agree-probe in C, inherited by $\mathrm{T}$, raises the full DP [the (driver, picture) of which] to [spec,T], the two operations proceeding in parallel."

${ }^{7}$ Another problem worth exploring is the status of extractions from argument DPs placed in the [spec,V] position in double object constructions:

(i) ?Of which boys did John put pictures of which boys on the table?

(ii) ?Of which associations did John give chairmen of which associations $\$ 30$ each?

The current prediction is that this case should be as good as (3a).

${ }^{8}$ Chomsky (2005: 13): "It remains to explain why the probe for wh-movement cannot readily access the whphrase within the external argument of $([\mathrm{vP}]$ in $(3 b)$. That could reduce to a locality condition: which in $[(3 b)]$ is embedded in the lower phase, which has already been passed in the derivation. We know that the external argument itself can be accessed in the next higher phase, but there is a cost to extracting something embedded in it."

${ }^{9}$ Chomsky (2005: 16): "It must be then that the [spec,T] position is impenetrable to EF (edge feature), and a far more natural principle would be that it is simply invisible to EF [...] That principle generalises the inactivity condition of earlier work, which takes the head of an A-chain (which always has any uninterpretable features valued) to be invisible to Agree."

${ }^{10}$ Chomsky (2005: 16-17): "In (3b), as already discussed, the EA [the (driver, picture) of which] raises to $[\mathrm{spec}, \mathrm{C}]$ from its base position and we have the subject-island effect. But in (3d), the effect is obviated. These expressions have the status of extraction from the object, not subject [...] That follows from the previous conclusions about IM, assuming the (still mysterious) condition EPP, which requires A-movement to pass through [spec,T], with familiar consequences for binding, and possibly reconstruction. One permitted order of operations is this: the Agree feature of C-T raises EA step-by-step to it final position, and along the way the edge-feature of $\mathrm{C}$ extracts the $\mathrm{PP}$ complement and raises it to [spec,C], with no deep search required because no phase boundaries are crossed." 
2. New rules for the derivation

Chomsky's new paper puts forward a few new postulates concerning the details of the derivation. The process of feature spread affects not only the relation between $\mathrm{C}$ and $\mathrm{T}$ but also the relation between any phase head and the lexical item it selects for (Chomsky 2005: 14-16). As a consequence, $v$ needs to bequeath its $[+\varphi]$ features (and possibly $\mathrm{EPP}$ ) to $\mathrm{V}$, while retaining the $\mathrm{EF}$ (edge feature). This procedure changes a few details in the derivation. Let us consider two derivations in the earlier phase model:

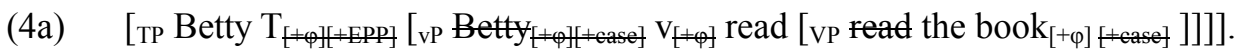

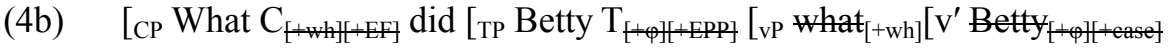

$\mathrm{V}_{[+\varphi \varphi][+E F\}}$ read [VP read what $[+\varphi][+$ ease][++wh] $\left.\left.\left.\left.]\right]\right]\right]\right]$

In example (4a) we deal with two Probe/Goal relations; the head of vP acts as a Probe toward the object DP and values the case feature of the object, while the interpretable $[+\varphi]$ features of the object value the uninterpretable $[+\varphi]$ features of the Probe. No movement takes place, as $\mathrm{v}$ does not carry feature [+EPP], a feature that causes displacement. The second Probe/Goal relation concerns T and the subject. This time Agree $([+\varphi]$ and $[+$ case] feature valuation) is accompanied by displacement, as $\mathrm{T}$ carries the $[+\mathrm{EPP}]$ feature.

Example (4b) is more complex, as here $v$ does not only value the case of the object and its own $[+\varphi]$ features, but also causes movement of the object to outer [spec,v], as it is equipped with the [+EPP] feature. ${ }^{11}$ In a sense, v played a sort of hybrid role in minimalist thinking: it acted as an A-type head for case checking and an A-bar type head for cyclic movement. Certainly, the movement of the object to [spec,v] voids the effects of PIC and makes it accessible to a higher Probe C. The derivational function of T is analogous to example (4a) but for a minor issue of intervention. At the point of merging $\mathrm{T}$ with $\mathrm{vP}$, the presence of what in the outer [spec,v] position interferes with the search of the T Probe for its Goal (Betty). Thus, this Agree relation must be countercyclic and follow the Agree between $\mathrm{C}$ and what and the subsequent evacuation of the latter to $[\mathrm{spec}, \mathrm{C}]$. This countercyclicity is not a problem if all principles apply at the phase level and when $\mathrm{CP}$ has been completed and all Agree relations established.

These derivations look slightly different in the new phase-based model.

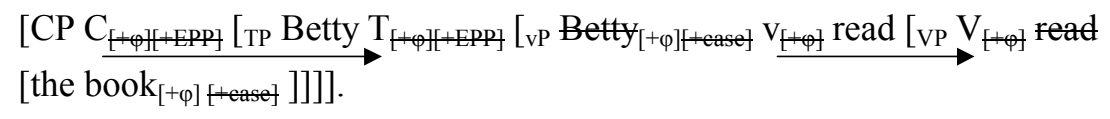

\footnotetext{
${ }^{11}$ As a matter of fact Chomsky (2005: 6) takes edge feature (EF) to be a feature that drives both EM (External Merge) and IM (Internal Merge). Thus v (or any other head having a complement and projecting a specifier) must be equipped with a double or triple EF; one responsible for the combination of $\mathrm{v}$ and $\mathrm{VP}$ into $\mathrm{vP}$, another responsible for the formation of the inner [spec,v] and yet another one responsible for the formation of the (outer) specifier of vP.
} 


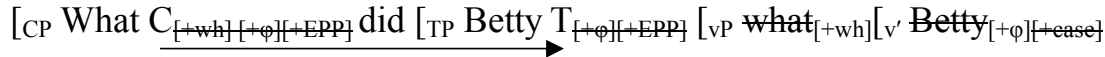

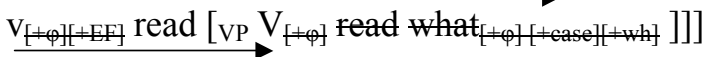

In example (5a) $\mathrm{T}$ inherits its $[+\varphi]$ features and EPP from $\mathrm{C}$ and $\mathrm{V}$ inherits its $[+\varphi]$ features from $\mathrm{v}$. These processes are indicated with arrows. As $\mathrm{V}$ does not inherit any EPP feature in this case the object does not move to [spec,V], although it is possible even in English (Object Shift), as Chomsky mentions, especially in ECM constructions discussed at length in Lasnik (1999). Probe T inherits both $[+\varphi]$ features and EPP from C, thus the subject is moved to [spec,T], though originally the feature causing the movement resided in $\mathrm{C}$. What follows from the discussion in this section is that feature EPP is coupled with $[+\varphi]$ features and, more generally, phase heads $(\mathrm{C}$ and $\mathrm{v})$ bequeath their A-type (L-related) head features to their complement heads (T and V) and retain their A-bar type edge features. A and A-bar properties originally do not follow from the positions in which given items land, but from the type of features that affect them. Probing for $[+\varphi]$ features and EPP forms an A-type dependency, while probing for edge features (like [+wh]), forms an A-bar type dependency. Hence, the dual derivational character of the head of $\mathrm{vP}$ is abandoned; following feature spread, $\mathrm{v}$ functions as an A-bar type head and V as an A-type head.

Crucial aspects of the derivation in (5b) are as follows: $\mathrm{V}$ inherits $[+\varphi]$ features from $\mathrm{v}$ and acts as a proxy Probe against Goal what, valuing its case feature and its own agreement features. The head of $\mathrm{vP}$ also acts as a Probe against what in its base position and the EF retained by $\mathrm{v}$ leads to the displacement of what to outer [spec, v]. T inherits $[+\varphi]$ features and EPP from $C$ and forces the valuation of the case feature of the subject (introduced via External Merge into inner [spec,v]) and its raising to [spec,T], again countercyclically. $\mathrm{C}$ retains its $\mathrm{EF}$, the $[+$ wh] feature to be precise, and searches for a compatible Goal at the edge of the vP phase. As a result what moves to [spec, $\mathrm{C}]$ without violating the PIC.

It is interesting to note that in previous minimalist accounts Object Shift (taken to be a combination of Agree and Move), placed the object at the edge of the $\mathrm{vP}$ phase. This introduced an unwelcome complication in the form of the Defective Intervention Constraint evoked by the object screening the subject from its Probe, as in the analysis in Chomsky (1995). Consider the syntactic object formed by the External Merge of T:

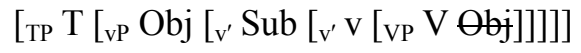

Probe $\mathrm{T}$ has problems reaching the subject across the fronted object. In English this derivational complication is fatal, unless the object is moved (e.g. via Wh-movement) or the crossing movement of arguments is explained through a concept of representational or derivational equidistance.

In Chomsky's new account Object Shift does not interfere with the relation Agree holding between $\mathrm{T}$ and the subject, as the case position of the object is still lower than 
the thematic position of the subject. For all intents and purposes, this analysis introduces the consequences of the split VP hypothesis of Koizumi (1995) and Lasnik (1999) into phase-based derivations:

$$
\text { [тр T [vp Sub [v' v [vp Obj [v, V Obj]]]]] }
$$

Probe $\mathrm{T}$ and the subject can be easily related to each other, as the object has been fronted to a lower position.

\section{Control as Raising and Raising as Control}

It seems to us that a prediction of Chomsky's new paper that is worth testing concerns the problem of extraction from DPs in control and raising constructions: does extraction from within an argument DP in a control infinitive make a difference? Theoretically it should, as the control chain (based on Landau 2000, 2004, 2007; and Bondaruk 2004) includes only the thematic position of the controller and its surface position: neither should be accessible to deep probing. Consider the examples below where the Subject Island Condition is violated:

(8a) ?Of which associations did chairmen seem to hush up the scandal?

(8b) ?Of which associations did chairmen try to hush up the scandal?

On the strength of Chomsky's arguments one would expect (8a) to be more acceptable than (8b). Example (8a) has the internal structure of a raising verb, analogous to (3d):

$$
\begin{aligned}
& \text { ?Of which associations did [тр chairmen of which associations seem } \\
& \text { [тр chairmen of which associations to [vP ehairmen of which associations } \\
& \text { hush up the scandal]]] }
\end{aligned}
$$

The intermediate landing site in [spec,T] constitutes the extraction site from the moved subject, as neither the PIC, nor the prohibition on extraction from the head of the chain position bars the movement of the PP.

As it is, however, both examples in (8) sound equally (un)acceptable, yet the deep probing in (8b) seems to violate the prohibitions in (1). Consider the details of this construction in (10) below:

(10) ?Of which associations did [TP chairmen of which associations] [vP chairmen of which asseciations try [СР [Tе PRO to [ [v PRO hush up the scandal]]]]]?

Obviously, neither position of chairmen of which associations is available to deep probing; extraction from within the subject placed in the thematic position violates the PIC, while extraction from the $[\mathrm{spec}, \mathrm{T}]$ position is impossible, as this is the head of the A-chain. 
Unless, as some scholars propose (Hornstein 2000, 2003; Boeckx and Hornstein 2004), control is raising and the structure in (8b) is very similar to the one in (9). This structure is presented in (11) below:

(11) Of which associations did [тр chairmen of which associations ${ }_{\mathrm{v} P}$ ehairmen of which associations try [TP ehairmen of which associations to [vp chairmen of which associations hush up the scandal]]]]?

The subject chairmen of which associations is merged in the position of [spec,v]. This position is not transparent to deep search from the combined C-T probe, though the subject itself can be moved as a whole. The position of the subject at the head of its Achain in [spec,T] is opaque to deep search as well, otherwise the effect of the Subject Condition would not show at all (see 2). The only logical explanation for the possibility of splitting the subject is that the deep search accesses the position of embedded [spec,T], which cannot be occupied by PRO but by the copy of the controller.

This move, however, would be running counter to several frequently repeated claims concerning a different status of $\mathrm{CP}$ (control) and TP (raising) infinitives, such as independence at PF, topicalisation, etc. Yet, the fact that both (8a) and (8b) sound equally (un)acceptable can be taken as an argument in favour of the account of control as movement. It must be emphasised that the PF independence of CPs and vPs versus other maximal projections is far from well established. Consider the case of passive participles or predicative adjectival phrases that can be fronted without qualifying for phasal status:

(12) Peter promised to get fired on Friday and [[vp fired on Friday] he got $t_{\mathrm{VP}}$ indeed]!

(13) He told me that car would be pretty and [[AP pretty] it was $t_{\mathrm{AP}}$ indeed]!

There is, however, another factor here as well. If native speakers judge both examples in (8) unacceptable, then Chomsky's example in (3d) does not show that the violation of the Subject Condition is allowed with raising but merely that there is some peculiarity of the extraction from the subject involved in the ... be likely... construction. This would put a totally different complexion on the issue of the apparent Subject Condition violations. ${ }^{12}$

\section{Simultaneous Multiple Agree instead of Repeated Multiple Agree}

The new concept of the derivational and feature valuation procedure presented in sections one and two sheds new light on cases of multiple agreement.

\footnotetext{
${ }^{12} \mathrm{As}$ a $P S i C L$ reviewer points out, be eager can be considered an equivalent control construction to (3d). If so, the sentence: Of which associations are the chairmen eager to cause a scandal? sounds equally (un)acceptable as Chomsky's example in (3d), which seems to prove our point.
} 
Chomsky (2005) expresses the conviction that only the heads heading phases can get involved in Probe/Goal relations, as these relations are relevant for operation Transfer (to LF and PF) ${ }^{13}$ He explicitly claims that participles (and presumably predicative adjectives) cannot agree with their subjects, but agreement in these cases is a product of the Probe C-T agreeing with both the nominal subject and the participle/adjective. ${ }^{14}$ Thus the representation in (14b) shows the preferred mode of feature valuation (Simultaneous Multiple Agree), while (14a) pictures a more problematic option of Repeated Agree (the arrow indicates operation Agree):

(14a) $\quad[$ TrP $\operatorname{Sub} T[$ Ap/PrtP $\{\mathrm{Sub}\}$ A/Prt $\{\mathrm{Sub}\}]$

(14b) $\quad[$ тт Sub T [AP/PrtP A/Prt $\{\operatorname{Sub}\}]$

In example (14a) the medial position of the subject in its A-chain would obviate the Subject Condition, which is not the case in English. ${ }^{15}$

Sometimes the agreement pattern can be quite complex; yet this strain can be borne by Chomsky's new proposals. Consider the following construction with a regular or quirky agreement pattern in Polish with a quantified subject:
Dwa tysiące
listów
zostały wysłane.
two thousand-NOM letters-GEN,PL were-PL sent-NOM,PL
'Two thousand letters were sent.'
Dwa tysiące
listów
zostało
wysłanych.
two thousand-NOM letters-GEN,PL was-NEUT,SG sent-GEN,PL
'Two thousand letters were sent.'

Both versions are acceptable, and both are interesting for our purposes. The exact mechanism of feature valuation by the subject is not the central issue here, although it must be very interesting. It appears that the participle agrees with the numeral quantifier for case and number and the auxiliary verb agrees with it for number only. This construction shows that, at least at the observational level, that the quantifier can appear either in the Nominative case or in the Accusative case (according to the so-called Accusative Hypothesis of Przepiórkowski 2004).

\footnotetext{
${ }^{13}$ Chomsky (2005: 9): It also natural to expect that along with Transfer, all other operations will also apply at the phase level, as determined by the label/probe. That implies that IM should be driven only by phase heads.

${ }^{14}$ Chomsky (2005: 21) argues that the stopover in the raising of the subject to [spec,T] at [spec,Prt] or [spec,A] would allow for deep probing and subject splitting in simple clauses with participles or predicative adjectives, contrary to fact. We return to this point in a further section.

${ }^{15}$ For instance: * Of which company is the chairwoman pretty/fired.
} 
In most cases agreement between the DP and another head is taken as an overt reflex of a syntactic process of feature valuation and the case of (15) does not look different. Regular agreement with participles and adjectives is treated as agreement between tensed T, the subject DP and the participle/adjective, ${ }^{16}$ probably under Multiple Agree (Hiraiwa 2001) ${ }^{17}$ If the subject is Nominative, the auxiliary verb and the participle are Goals valued by the T Probe in the standard manner. When the subject is Accusative, the T probe values the participle and the auxiliary in a defective manner, hence default agreement shows on them (3 p.sg.neut. on the auxiliary and 3p.pl.Gen on the participle).

\section{The That-trace Effect remains a puzzle}

Yet another problem concerns that-trace phenomena; what is the reason for these effects in the current account? Especially, as according to Chomsky (2005: 15) there is no evidence for the chain holding between [spec,C] and [spec,T], whose well- or illformedness formed the basis of the That-trace Effect accounts both in the GB tradition (Koopman 1983; Rizzi 1990) and the Minimalist Program (Pesetsky and Torrego $2000)^{18}$ The account of the latter (Pesetsky and Torrego 2000) seems appealing in many ways, as it manages to provide unanimous explanation for the syntactic problems otherwise considered (seemingly) unrelated. Some of them are listed under (16).

\footnotetext{
${ }^{16}$ Chomsky (2005: 10) deals with participial agreement in the following manner: When features appear morphologically at $\mathrm{T}$ without tense (or in participles, etc.), they should therefore be regarded as just a morphological effect of agreement, without significance in the syntactic computation. Yet, this agreement is not defined further and the term is used for Agree (Chomsky 2005: 15: "[...] the $\mathrm{v}^{*}$-phase $\mathrm{v}^{*}$-John agreement values all uninterpretable features"). Participle/adjective agreement cannot be the result of the spec/head configuration, as m-command is no longer a useful grammatical relationship. (Chomsky 2005: 12: "It follows that there should be no m-command, hence no spec/head relations, except for the special case the spec itself can be a probe. That requires considerable rethinking of much important work, especially on agreement.")

${ }^{17}$ Hiraiwa (2001) analyses constructions involving multiple feature checking or Agree; in Japanese raisingto-subject constructions both the matrix and the embedded subjects can be marked Nominative by matrix $T$ (Hiraiwa 2001:76):

\begin{tabular}{llllll} 
John-ga/ni & [mada & Mary ga & \multicolumn{1}{c}{ kodomo-ni } & amaku $]$ & kanjita. \\
John-NOM/DAT & still & Mary-NOM & children-DAT & lenient-INF & feel-PST \\
'Mary seems to John to be still lenient to children, & &
\end{tabular}

${ }^{18}$ Chomsky (2005: 15): "It has been conventionally assumed that in constructions such as Who saw John and Who arrived, there is an A-chain formed by A-movement of the wh-phrase to [spec, T], and an $\mathrm{A}^{\prime}$-chain formed by $\mathrm{A}^{\prime}$-movement of the subject to [spec,C]. There was never any real justification for assuming that there are two chains, a uniform A-chain and a non-uniform $\mathrm{A}^{\prime}$-A chain, rather than one $\mathrm{A}^{\prime}$-A-A chain formed by successive-cyclic raising of the wh-phrase to $[\mathrm{spec}, \mathrm{T}]$ and then to $[\mathrm{spec}, \mathrm{C}]$. We now see, however, that the intuition is justified. There is no direct relation between the wh-phrase in [spec,C] and in [spec,T] and no reason to suppose that there is a non-uniform chain at all: just the argument A-chains and an operatorargument construction."
} 
(16) That-trace related phenomena

(16a) $\mathrm{Who}_{\mathrm{i}}$ do you think (*that) $\mathrm{t}_{\mathrm{i}}$ killed Bill?

(16b) Who $\mathrm{W}_{\mathrm{i}}$ do you think (that) Bill killed $t_{\mathrm{i}}$ ?

(16c) That $/ * \varnothing$ George will leave was claimed by everyone.

(16d) Bill claimed that $/ \varnothing$ Mary will leave at seven.

(16e) $\mathrm{Who}_{\mathrm{i}}$ *did buy/bought the book?

(16f) ?[CP How ${ }_{\mathrm{i}}$ do [IP you think [CP $\mathrm{t}_{\mathrm{i}}\left(\varnothing /\right.$ that) [IP John finished the course $\left.\left.\left.\mathrm{t}_{\mathrm{i}}\right]\right]\right]$ $\left\{\mathrm{t}_{\mathrm{i}}:-\chi\right.$ at $\left.\mathrm{SS}\right\}$

$(16 \mathrm{~g}) *{ }_{\mathrm{CP}} \mathrm{Who}_{\mathrm{i}}$ do [IP you think [CP $\mathrm{t}_{\mathrm{i}}(\varnothing / *$ that $)$ [IP $\mathrm{t}_{\mathrm{i}}$ finished the course $\left.\left.]\right]\right]$ $\left\{*{ }^{*}:-\chi\right.$ at $\left.\mathrm{SS}\right\}$

The Principles and Parameters account of the problems collected under (16) appears fairly complex in that it incorporates a vast amount of principles and additional mechanisms. These concern predominantly the Empty Category Principle along with $\theta$ Government requirement, Subjacency, or $\chi$-marking (Lasnik and Saito 1984). Despite extensive descriptive coverage, the approach fails to resolve some major remaining problems. For example, as Pesetsky and Torrego (2000: 3) point out, "more serious, however, was the overall failure of ECP research to explain why subjects should have a special binding requirement in the first place [...] the ECP stipulated the difference, and various attempts were made to rationalize it [...] but the explanation was never found".

The computational model developed in Pesetsky and Torrego (2000) attempts to provide principled solutions to (16) by suggesting a fairly convincing, minimalist theory based on some major assumptions listed below:

(17) Feature Movement (Chomsky 1995, 1999)

(17a) Move $\mathrm{F}$ - a repair strategy by which an uninterpretable feature $\mathrm{F}$ on the head $\mathrm{K}$ is deleted in response to movement to $\mathrm{K}$ of another instance of $\mathrm{K}$.

(17b) -/+ value: a distinguishing criterion for the uninterpretable/interpretable features: "uninterpretable $[\mathrm{uF}]$ feature (1) must be valued under Agree for NS derivation to converge; (2) once valued, must be eliminated from $D$; (3) it must be transferred to $\varphi[\ldots]$ TRANSFER has a 'memory' of phase-length" (Chomsky 2001: 14).

(17c) Agree - an unvalued feature F (a probe) scans its c-command domain for another instance of $\mathrm{F}$ (goal) with which to agree.

(17d) Goal as well as Probe must be active for Agree to apply (Chomsky 1999: 5, 3i).

(17e) Failure to check/value the features of the attractor (probe) results in nonconvergence.

(17f) Movement for any purpose other than the consequence of the Probe-Goal relation is banned. 
(17g) The combination of Agree/Pied-Pipe/Merge is the composite operation Move, pre-empted where possible by a simpler operations Merge and Agree (Chomsky 1999: 14).

(17h) EPP (see also OCC, Chomsky 2001) on a given feature drives overt movement. ${ }^{19}$

Consider the example of A-movement of the NP/DP-Subject (Spec,vP-Spec,TP), illustrated below as (18).

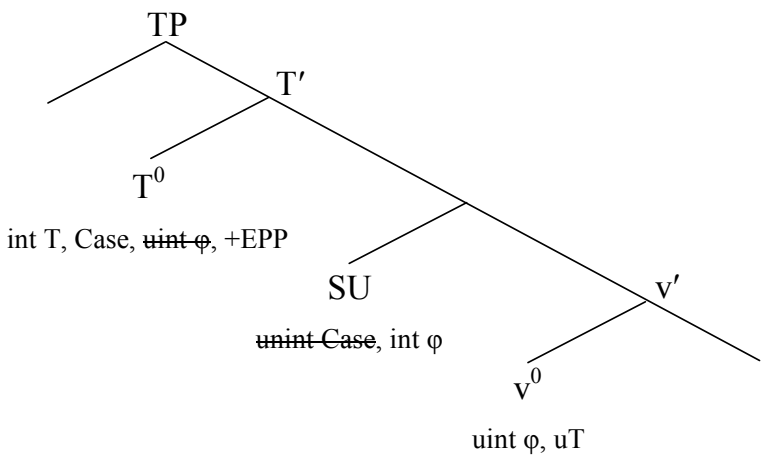

$\mathrm{T}^{0}$ has, among other features, an uninterpretable $\varphi$ with [+EPP] (17h). For purposes of feature valuation, $\mathrm{T}^{0}$ probes its c-commanding domain in order to find a potential Goal (17b). The NP/DP in the position of Spec,vP seems the closest available Goal (17d), i.e. it can satisfy $\mathrm{T}^{0}$, s features as well as its own uninterpretable Case (see also Maximize Matching Effects, Chomsky 1999: 13). The Probe-Goal relation results in Agree $(17 \mathrm{a}, \mathrm{c})$. Finally, pied-piping of the phonological material followed by Merge ensues as a consequence of $[+\mathrm{EPP}]$ on $\mathrm{T}^{0}$, s uninterpretable $\varphi(17 \mathrm{~g}, \mathrm{~h})$.

Such a definition of Movement allows the authors to preserve the important minimalist criteria concerning its highly restrained character $(17 \mathrm{e}, \mathrm{f})$.

Pesetsky and Torrego's T-C scenario requires a number of interesting assumptions. Primarily, it is claimed that movement obeys Principle of Minimal Compliance (Richards 1997, 2001), given below:

\footnotetext{
${ }^{19}$ Pesetsky and Torrego (2000) do not treat EPP as an independent feature; rather, they see it as a trigger for movement on a given feature. Thus, for example, in standard British English, $\mathrm{C}^{0}$ is equipped with an uninterpretable feature T (uT) which is -EPP, whereas in Belfast English the feature has a +EPP value. For further discussion, see (22) and (23).
} 
(19) Principle of Minimal Compliance (Richards (2001: 199)

If the tree contains a dependency headed by $\mathrm{H}$ which obeys constraint $\mathrm{C}$, any syntactic object $\mathrm{G}$ which $\mathrm{H}$ "immediately c-commands" ${ }^{\text {" } 20}$ can be ignored for purposes of determining whether $\mathrm{C}$ is obeyed by other dependencies.

Another important assumption concerns the featural configuration of $\mathrm{C}^{0}$. In particular, $\mathrm{C}^{0}$ is claimed to have, among others, uninterpretable Tense with [+/- EPP], depending on its distribution and function (e.g. matrix, embedded, declarative, interrogative, etc.). Simultaneously, that, traditionally classified as a complementiser, is treated as an instance of $\mathrm{T}^{0}$ "doubling" the tensed verb; the movement of T-C thus satisfies C's uT [+EPP]. Most crucially though, Pesetski and Torrego's theory relies on postulating Nominative Case to be an overt expression of $\mathrm{uT}$ on $\mathrm{D}$, thus allowing movement of subject NP/DPs to $\mathrm{C}^{0}$ as yet another way of checking uT [+EPP] on $\mathrm{C}^{0}$. The postulate seems to have substantial empirical motivation coming from languages Pittapitta ${ }^{21}(\mathrm{Pe}-$ setski and Torrego 2000: 8) as illustrated below:

$$
\begin{aligned}
& \text { Ngapiri-ngu thawa paya-nha } \\
& \text { Father-NOM.SG.FUT kill bird-ACC.SG } \\
& \text { 'Father will kill the bird (with missile thrown).' }
\end{aligned}
$$

To the extent the linguistic observations of Pittapitta are reliable, the presence of a tense affix on a nominative NP/DP provides empirical support for Pesetsky and Torrego's (2000) postulates. As yet another interesting fact, they refer to the similarity between Nominative Case (NP/DP) affixes and Mood (V) affixes in Classical Arabic (Pesetsky and Torrego 2000: 8).

The list in (21) summarises the basis for the computational mechanics of T-C:

(21) The Computational Mechanics of T-C:

(21a) uT [+EPP] present on $\mathrm{C}^{0}$.

(21b) Nominative Case is uT on D.

(21c) Movement obeys economy (number of operations, locality).

(21d) PMC (Richards 1997, 2001).

(21e) that - doubles the tensed verb, moved to $\mathrm{C}^{0}$.

(21f) EPP as a property of features (e.g. uT [+/-EPP]).

The sentences given as (22) and (23), instances of Standard English (SE) and Belfast English (BE), respectively, exemplify the approach described in (17) and (21). Primar-

\footnotetext{
${ }^{20}$ Richards (2001: 199): “A immediately c-commands B iff the lowest node dominating A dominates B and there is no C such that A asymmetrically c-commands C and C asymmetrically c-commands B."

${ }^{21}$ A language of North Queensland, Australia.
} 
ily, consider the way in which the features of $\mathrm{C}$ are checked by the respective lexical items. The $\mathrm{uT}$ on the intermediate $\mathrm{C}^{0}$ has the property [+EPP]. Thus, it triggers overt movement of that in (22), as it is an instance (i.e. a doubling of) T. In (23), though, the $\mathrm{uT}$ on $\mathrm{C}$ is satisfied by the overt movement of will.

What ${ }_{\mathrm{i}}$ did Bill think $\left[\mathrm{t}_{\mathrm{i}}\left[\mathrm{that} / \varnothing\left[\mathrm{C}_{\mathrm{uT}[+\mathrm{EPP}], \mathrm{tWh}[+\mathrm{EPP}]}\right]\right.\right.$ George will say $\left.\left.\mathrm{t}_{\mathrm{i}}\right]\right]$

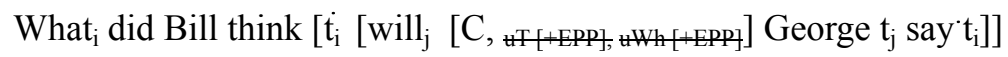

Consider further the way in which Pesetsky and Torrego's proposals deal with other, that-trace related linguistic facts.

(24a) Bill asked [CP what $\left[\right.$ $\left[\mathrm{C}\right.$, $\left.{ }_{\mathrm{tT}}[-\mathrm{EPP}], \mathrm{tWh}_{\mathrm{H}}+\mathrm{EPP}\right]$ Mary bought $\left.\mathrm{t}_{\mathrm{i}}\right]$

(24b) *Bill asked [CP What $t_{i}$ did [C, $\left.{ }_{\mathrm{tT}[-\mathrm{EPP}]}{ }_{\mathrm{tWWh}[+\mathrm{EPP}]}\right]$ Mary buy $\mathrm{t}_{\mathrm{i}}$ ]

(24c) $\quad\left[\mathrm{CP}_{\mathrm{Who}}[\mathrm{C}\right.$,

(24d) * [CP Who $\mathrm{Wh}_{\mathrm{i}}$ did [C, uWh [+EPP, uT [+EPP] $] \mathrm{t}_{\mathrm{i}}$ find the car]?

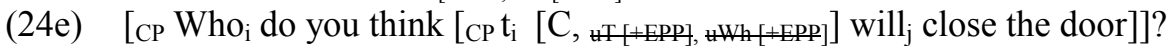

(24f) $*\left[{ }_{\mathrm{CP}} \mathrm{Who}_{\mathrm{i}}\right.$ do you think $\left[\mathrm{CP}_{\mathrm{i}}\left[\mathrm{that}_{\mathrm{j}}\left[\mathrm{C},{ }_{\mathrm{uT}[+\mathrm{EPP}\}, \mathrm{uWh}[+\mathrm{EPP}]}\right]\right.\right.$ will $\mathrm{j}_{\mathrm{j}}$ close the door $\left.]\right]$ ?

The minimalist spirit of the theory requires the derivation to proceed along the most economical paths (economy expressible here in terms of the number of operations). In particular, the wh-moved subject can potentially check both the uninterpretable features of $\mathrm{C}^{0}$; thus, no need arises for T-C movement. (24a, c, e) can be explained using this logic. $(24 \mathrm{~b}, \mathrm{~d})$ are thus instances of a redundant, thus illegitimate, T-C movement (uT [-EPP] feature checked in SE by Agree with the nominative NP/DP) in embedded and matrix CPs, respectively. Finally, (24f) illustrates an illicit (uneconomical) occurrence of $\mathrm{T}$ (i.e. that doubling the tensed $\mathrm{T}$ ) in the embedded $\mathrm{C}^{0}$; its uT feature has already been checked by the nominative wh-moving through its Spec.

Despite seemingly extensive explanatory potential of their theory (expressible both in the necessary descriptive machinery as well as significant unification of the numerous that-trace related phenomena) Pesetsky and Torrego's scenario cannot be readily reconciled with the new set of proposals for the syntactic derivation expressed by Chomsky (2005). Most importantly, as we have already pointed out, Chomsky's system assumes the features of $\mathrm{T}$ to be derivative from $\mathrm{C}$ (see note 4 ), yet it does not allow for any communication between the two heads in terms of T-C movement. Chomsky justifies his point by claiming the bifurcation between the two types of chains (i.e. A/A'). Therefore, the wh-movement from the subject position requires the formation of two independent chains (see note 2); $\mathrm{C}$ and $\mathrm{T}$ probes attract the two occurrences of the subject proceeding in parallel and resulting in two simultaneous, yet distinct (non-related) movements of the A and $\mathrm{A}^{\prime}$ type. The proposal along these lines seems to undermine the validity of Pesetsky and Torrego's (2000) application of derivational economy expressed in the number of operations. Consider once again examples $(16 \mathrm{a}-\mathrm{b})$ and $(24 \mathrm{e}-$ 
f), the standard instances of the That-trace Effect, the latter repeated here for convenience as $(25 \mathrm{a}-\mathrm{b})$ :

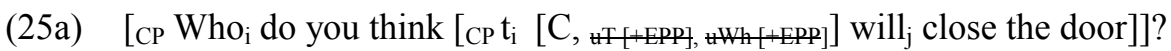

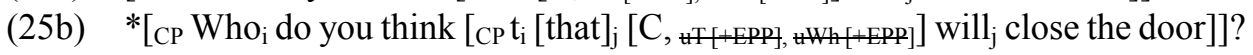

The account of (25a), whereby the auxiliary verb moves from $\mathrm{T}^{0}$ and checks the features of $\mathrm{C}^{0}$, falls outside the range of permissible solutions. What is more, it makes the job of explaining the ungrammaticality of (25b) extremely difficult; unless some other computational devices are worked out, the account seems to have no other option but to rely on the traditional, representational notions of locality, otherwise abandoned on different grounds (PIC). In a similar vein, examples like (16e), repeated here as (26), lose a principled explanation, thus bringing back into light the problem of the rootembedded asymmetry in the residual V2 in English:

$$
\text { Who }_{\mathrm{i}} \text { *did buy/bought the book? }
$$

Another problem concerns the obligatory presence of that in embedded declarative subject CPs, such as $(16 c-d)$, repeated here as (27):

(27a) [тр [ст That George will leave] was claimed by everyone]

(27b) *[тр [ср $\varnothing$ George will leave] was claimed by everyone]

For (27a), Pesetsky and Torrego (2000) suggest the obligatory presence of that as an instance of $\mathrm{T}^{0}$ (therefore, inherently in possession of an interpretable $\mathrm{T}$ feature) moved to $\mathrm{C}^{0}$ and checking its uT. Thus, despite checking, the T feature on $\mathrm{T}$ does not erase and the phrase (in this case - a phase) is still visible for attraction by a higher Probe. An ordinary DP, although, on Pesetsky and Torrego's scenario, moving from [spec,T] to [spec,C], possesses a $\mathrm{T}$ feature that erases as a result of valuation of the $\mathrm{uT}$ on $\mathrm{C}^{0}$. Therefore, the $\mathrm{CP}$ does not appear as a potential Goal for the higher Probe T, witness the ungrammaticality of (27b). The feature spread model of Chomsky (2005) outlaws any communication between $\mathrm{T}$ and $\mathrm{C}$. For that reason, the explanation of the phenomenon must probably resort to postulating the difference between (27a) and (27b) to be rooted in the phonological realisation of the complementiser, a solution that seemingly runs short of explanatory potential.

Finally, the phase-based system of Chomsky (2005) does not offer a satisfactory solution to the examples of the optional that in embedded CPs. Example (28) illustrates the point:

Bill claimed $\left[{ }_{\mathrm{CP}}\right.$ that $/ \varnothing$ Mary will leave at seven] 
As it has already been shown, Pesetsky and Torrego (2000) assume the $\mathrm{uT}$ on $\mathrm{C}^{0}$ to be checked either by that, the occurrence of Tense moving to C, or the subject DP itself. Banning the possibility of T-C/[spec,T] - [spec,C] movement leaves the facts unexplained or, rather, provides some technical solutions for one option only. Namely, it may be assumed that two parallel chains are formed. Thus, an A-chain [Mary, $\mathrm{t}_{\mathrm{i}}$ ] moves the $\mathrm{DP}$ to [spec, T]; in consequence, the features of both $\mathrm{T}$ and $\mathrm{D}$ are checked and the DP is frozen (see: 1a). Simultaneously, an $\mathrm{A}^{\prime}$ chain [Mary, $\mathrm{t}_{\mathrm{i}}$ ] results in the movement of the $\mathrm{DP}$ to $[\mathrm{spec}, \mathrm{CP}$ ], thus checking the features of $\mathrm{C}$. The solution does not strike as convincing, however, as it cannot be applied to explain the grammaticality of sentences with that in embedded declarative CPs.

To conclude, we assume the phase-based model of Chomsky $(2005,2006)$ incorporating the feature spread option to have little if anything to offer to the problems concerning the that-trace related linguistic phenomena. The otherwise unanimous (in Pesetsky and Torrego's terms) account holds for the computation allowing the communication between $\mathrm{T}$ and $\mathrm{C}$.

\section{The Anti-Subject Condition}

There is another aspect of the proposals in Chomsky $(2005,2006)$ that is worthy of closer scrutiny, namely the idea that only phase heads are probes. Any alleged evidence against this claim, such as the probing potential of $\mathrm{T}$, can be re-interpreted as a process of feature spread between the phase head and the head it selects.

It seems to us that this claim is fairly strong, far-reaching and indicating an interesting possibility for parametric variation among languages. There are languages in which the Subject Condition holds (e.g. English) and others, where it does not (e.g. Polish). Chomsky (2005) convincingly derives the Subject Condition, yet the question arises as to how its violations can be derived. Let us try to seek room for parametric variation within the picture of Agree and deep search proposed in Chomsky (2005). We outline two ways of deriving the Subject Condition Parameter; the first, call it the conservative one, is more in line with Chomsky's recent proposals, while the second is more radical and more distantly related to Chomsky's original ideas.

\subsection{The conservative derivation of the Anti-Subject Condition}

There is a rather natural room for parametric variation concerning the operation of the Subject Condition. As Chomsky observes (see note 14), any intermediate landing site in the A-chain of the subject raised from its thematic position to its surface position opens up a possibility of deep probing and successful extraction from within the subject DP. It has been observed that languages with rich verbal inflection frequently allow for Subject Condition violations. The point is that the correlation between rich verbal inflection 
and extraction from subjects is now easy to capture. Consider the structure below, it includes the well-known and equally well-forgotten AgrP but it could as well be called FP, a projection within the split IP:

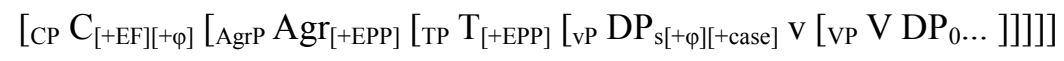

We can assume, following Thrainsson $(1966,2003)$ that languages like Polish (and probably also German) have split IP, as indicated by the complex morphology on the inflected verb and the presence of Transitive Expletive Constructions (TECs) in these languages. For instance in Polish the subject usually moves up to [spec,Agr], whereas in German it can either terminate its A-chain in [spec,Agr] or move to [spec,C] in the SVO order in main clauses. The consequence of this state of affairs is that the functional head of $\mathrm{T}$ in such languages can act like the head of $\mathrm{T}$ in English raising constructions: it is equipped with the [+EPP] feature but it is not the terminal position in the A-chain formed by the subject. Hence, deep search of the EF from C can access the subject DP in [spec,T], exactly as in the English example of subject raising. Thus the extraction from the subject is permissible and violates neither the PIC nor the "freezing" condition: ${ }^{22}$

(30a) ?Ilu może kandydatów z jednego kraju pretendować how many can candidates from one country apply

do Nagrody Nobla?

for the Nobel Prize

'How many candidates from one country can apply for the Nobel Prize?'

(30b) ?Ten mógł poeta zamieszkać w tym domu. this could poet lodge in this house

'This poet could lodge in this house.'

(30c) Ein Bericht über Boris Becker wird der Zeitung nützen. a report about Boris Becker will the newspaper-DAT be-of-use 'A report about Boris Becker will be useful to the newspaper.'

(30d) ?über Boris Becker wird ein Bericht der Zeitung nützen. about Boris Becker will a report the newspaper-DAT be-of-use

(31) [CP ilu C-może [AgrsP ilu kandydatów z jednego kraju Agr-może [тр ilukandydatów z jednego kraju T-może [vP [NP ilu kandydatów z jednego kraju] pretendować do nagrody Nobla]]]]

${ }^{22}$ Such examples are not perfect stylistically but are frequently found in "high style" and poetry. 
(32a) [CP ten C-mógł [AgrsP poeta Agr-mógł [TP ten poeta T-mógł [ ${ }_{\mathrm{vP}}$ [NP ten poeta] zamieszkać w tym domu]]]]

(32b) [cP über Boris Becker C-wird [AgrsP ein Bericht über Boris Beeker Agr-wird [TP ein Bericht über Boris Becker T-wird [vp ein Bericht über Boris Becker der Zeitung nützen]]]]

The structures in (31) and (32) illustrate the fact that the medial position in the subject chain is accessible to deep probing and extraction. ${ }^{23}$ Certainly, this extraction is subject to language particular requirements, for instance Polish does not allow for Preposition stranding but does allow for the extraction of the Left Branch.

\subsection{The radical derivation of the Anti-Subject Condition}

The locus for parametric variation can also lie in the phenomenon of feature spread involving $\mathrm{C}$ and $\mathrm{T}$. The possibility of the spread can give triple results:

\section{C-T feature spread:}

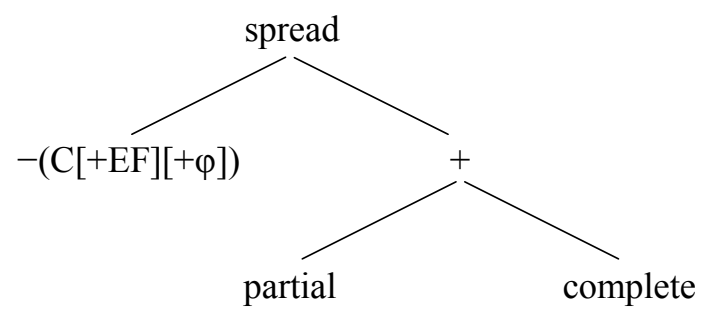

The diagram in (33) shows that there could be languages in which feature spread does not take place, that is the head of the $\mathrm{CP}$ phase does not transfer its $[+\varphi]$ feature onto the head $\mathrm{T}$ it selects. It therefore shows combined properties of $\mathrm{C}$ and $\mathrm{T}$ from earlier ap-

\footnotetext{
${ }^{23} \mathrm{~A} P S i C L$ reviewer suggests using multiple specifiers of $\mathrm{T}$ in this representation rather than single specifiers of two independent heads. We believe, however, that it would be very problematic within current minimalism to justify movement between two specifier positions of the same head. If movement is driven by the need for feature valuation and features rests with heads/probes, then if phrase A becomes a specifier of $\mathrm{X}$, it can value/be related to all features of $\mathrm{X}$. Thus its further movement within the domain of head $\mathrm{X}$ is redundant.
} 
proaches. We take German (and probably all V2 Germanic languages) to allow for this option in matrix clause Subject-Verb-Object word order arrangements. ${ }^{24}$

On the other hand, there are languages where $C$ transfers its $[+\varphi]$ features to $T$. These languages fall into two types. While in certain languages (say, Polish) T can act as an independent probe at some derivational step, in others it can act as such only at a later derivational step, when c-commanded by $\mathrm{C}$ introduced by External Merge (this is the case of English). This difference plus certain assumptions concerning the left periphery of the clause (the $\mathrm{CP}$ area) seem to have relevant consequences for the presence or absence of the Subject Condition effect.

Let us consider a question that pertains to the difference between the phase-based system in Chomsky $(1998,1999,2001)$ from the one in Chomsky $(2005)$ in this respect: how is Nominative case valued? In the former account $\mathrm{T}$, although obligatorily selected by $\mathrm{C}$, acts as an independent probe and accesses the subject in its thematic position in $[\mathrm{spec}, \mathrm{v}]$. The complete set of $[+\varphi]$ features on $\mathrm{T}$ is valued by the set of $[+\varphi]$ features on the DP serving as Goal, whose [+case] feature is valued as well, whereas the [+EPP] feature drives the raising of the subject. This derivational step is represented below:

$$
\left[\mathrm{TPP}_{[+\varphi][+E P P]}\left[\mathrm{vp}_{\mathrm{vP}} \mathrm{DP}_{\mathrm{s}[+\varphi][+ \text { case }]} \mathrm{v}\left[\mathrm{vP} \mathrm{V} \mathrm{DP}_{0} \ldots\right]\right]\right]
$$

Two properties of this system seem relevant for our discussion. First, the phase head C is not merged into the system yet, thus on the basis of the definition of the Phrase Impenetrability Condition vP is not a phase at this stage. A reminder of the PIC may prove convenient at this point:

(35) Phase Impenetrability Condition (Chomsky 1999: 10)

The domain of $\mathrm{H}$ is not accessible to operations at $\mathrm{ZP}$, but only $\mathrm{H}$ and its edge. (where: ZP is the least strong phase and the edge consists of specifiers)

There is a plausible reading of this definition on which the projection of $\mathrm{v}$ becomes a phase only after the next phase-head (here, $\mathrm{C}$ ) has been merged into the syntactic object currently formed by the derivation.

Second, T can access both the subject DP and the object DP to the same extent, as both are placed in their base positions and neither is separated from $\mathrm{T}$ by a phase boundary.

The hypothesis presented in Chomsky $(2005,2006)$ puts much stronger demands on the process of valuing the features of the subject. $T$ is no longer viewed as a separate probe: it can only function as a proxy for the phase head, which values the case of the subject as a result of feature spread:

\footnotetext{
${ }^{24}$ In such constructions the subject also serves as the topic, so $\mathrm{C}$ can license this functional reading by its [+EF].
} 
(36)

$$
\begin{aligned}
& \text { Feature Spread: } \\
& \mathrm{C}_{[+\varphi][+E P P][+E F]} \ldots \mathrm{T} \rightarrow \mathrm{C}_{[+E F]} \ldots \mathrm{T}_{[+\varphi][+E P P]}
\end{aligned}
$$

Thus the configuration of Nominative case licensing under the feature spread hypothesis looks as follows:

$$
\left[{ }_{\text {CP }} \mathrm{C}_{[+\mathrm{EF}]}\left[\mathrm{TrP} \mathrm{T}_{[+\varphi][+\mathrm{EPP}]}\left[\mathrm{vp} \mathrm{DP}_{\mathrm{s}[+\varphi][+ \text { case }]} \mathrm{v}\left[\mathrm{vP} \mathrm{V} \mathrm{DP}_{0} \ldots\right]\right]\right]\right]
$$

In the representation in (37) the subject DP is placed in the [spec,v] position which is the edge of the phase, as the Probe accessing the NPs Goal is actually a C-T probe, with $\mathrm{C}$, the next phase head, playing an active part.

Assume that the operation of feature spread shown in (36) can be taken to be either a part of the computation in narrow syntax (from initial numeration to LF) in some languages, or an operation taking place in Initial Numeration, say a consequence of operation Select assigning features $[+\varphi]$ and $[+\mathrm{EPP}]$ to $\mathrm{T}$. If so, the alternating order between the operations of feature spread and the merger of $\mathrm{T}$ leads to a different status of the $\mathrm{vP}$ projection in both derivations. In (34), vP is not a strong phase and both the subject DP and its sub-components can be accessed by $\mathrm{T}$ and any other probes up to $\mathrm{C}$, whereas in the derivation shown in (37) is placed at the edge of the phase and its sub-components cannot be accessed.

If the order between feature spread and merger of $\mathrm{T}$ is subject to parametric variation, we could account for the difference between such languages as English, where the Subject Condition must be strictly observed and is loosened only in the case of raising constructions, and languages such as Polish, where the Subject Condition is not observed.

Bošković (2002) proposes that Slavic Wh-movement does not always target the position [spec,C] but can, subject to parametric variation, also target the head of Focus phrase, placed in the complement domain of C. Lubańska (2005) shows that this mode of Wh-movement is true for Polish as well. If Bošković's and Lubanska's assumptions concerning Wh-movement in Polish are adopted, it can also be claimed that Foc is not a phase head. Consider the following example, bearing in mind that feature spread precedes the merger of $\mathrm{T}$ in Polish and Left Branch Condition violations are admitted:

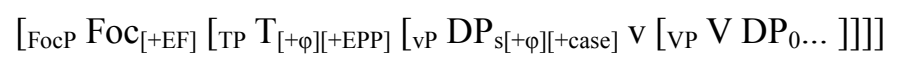

Assuming that $\mathrm{C}$ is the phase head, at the stage of the derivation indicated in $(38) \mathrm{vP}$ is not a phase yet, so the base position of the subject is accessible to deep probing from the head of FocP equipped with the edge feature [+EF]. In this spirit, consider example (31) again:

(39) [FocP ilu Foc-może [TP [NP ilu kandydatów z jednego kraju] T-møże [vP [NP ilu kandydatów $z$ jednego kraju] pretendować do nagrody Nobla]]] 
The left branch of the subject NP (ilu) is separated from the remnant in the base position and moved to [spec,Foc]. Consequently, the Subject Condition is voided.

We have thus identified two possible ways of violating the Subject Condition: through an articulated IP structure with an intermediate A-chain position for the subject and through a semi-independent $\mathrm{T}$ and $\mathrm{Wh}$-movement targeting a projection lower than the phase head C. ${ }^{25}$

7. Genitive of Negation as another case of feature spread

Incidentally, there is independent evidence for the feature spread proposed in Chomsky $(2005,2006)$. Witkos $(2004,2007)$ proposes an account of the Genitive of Negation in Polish on the basis of feature spread involving $\mathrm{v}$ and a functional head of Polarity Phrase. In this case, however, a Case assigning feature, typical of the head v, is spread up to the c-commanding head of the Polarity Phrase.

The Polish language shows the phenomenon of the Genitive of Negation, whereby nominal objects appearing in Accusative in affirmative clauses have to change into Genitive in negative clauses. ${ }^{26}$ Consider a few basic examples:

(40a) Piotr pali fajkę

Piotr smokes pipe-ACC

'Piotr smokes the pipe.'

(40b) Piotr nie pali fajki.

Piotr not smokes pipe-GEN

'Piotr does not smoke the pipe.'

(41a) Maria chce czytać gazetę.

Maria wants (to) read paper-ACC

'Maria wants to read a newspaper.'

(41b) Maria nie chce czytać gazety.

Maria not wants (to) read paper-GEN

'Maria does not want to read a paper.'

${ }^{25}$ It appears that the account of the Subject Condition presented in Chomsky (2005) is more flexible, conceptually and empirically adequate than the proposal presented in Uriagereka (1999). The latter theory predicts that the Subject Condition should be inviolable, as every complex subject forms an independent Command Unit that is immediately spelled out. The former account, as we have shown, seems to allow for language variation in this respect.

${ }^{26}$ Our presentation is only extremely cursory. This topic has attracted substantial attention in Polish generative linguistics; for detailed discussion see, among others, Willim (1990), Tajsner (1990), Witkoś (1998), Dziwirek (1998), Przepiórkowski (1999), Witkoś (2004) and Bondaruk (2004). 
Witkoś $(2004,2007)$ tries to capitalise on the idea, explicit in Chomsky (1999), that features marked for deletion are still accessible within the same phase. He claims that Chomsky's classification of Probes into complete and defective ones may be too coarse grained and proposes that there are thee types of Probes:

(42a) complete: $T_{[+\varphi, \text { case }]}, \mathrm{v}_{[+\varphi, \text { case }]}$

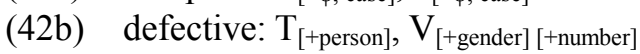

(42c) split: $\mathrm{Neg}_{[+ \text {case }]}, \mathrm{v}_{[++\varphi]}$

Crucially, the difference between (42b) and (42c) is that the combined Probe consisting of a defective $\mathrm{T}$ (lacking the full set of $\varphi$-features) and the participle (lacking the full set of $\varphi$-features) is still short of feature $[+ \text { case }]^{27}$ and is thus still incomplete. ${ }^{28}$ The "split" probe in (42c) looks like a result of feature spread: instead of appearing on one phasedefining head, features relevant for structural case checking appear on two heads placed within the same derivational phase.

This proposal seems to explain how Polish differs from English; the task of case licensing, performed in English by a single head, is spread onto two heads: the verb and Polarity/Negation. Chomsky $(1995,1998,1999)$ claims that relevant features are introduced into the computational procedure via lexical items that carry them. Consider the following assumption: the Probe can value case on the Goal DP only if it carries four features, instead of three usually regarded as the complete $[+\varphi]$ set: person, number gender and [ + case]. There is a parametric option according to which either all relevant features are assigned to one head or more than one head, English shows it in (43a) and Polish in (43b):

(43a) $\quad\left[\ldots \mathrm{v}_{[+ \text {pers, }, \text { num },+ \text { gen },+ \text { case }]} \ldots \mathrm{DP}_{[+ \text {case }]} \ldots\right]$

(43b) $\quad\left[\ldots\right.$ Polarity $[+$ case $\left.] \ldots \mathrm{v}_{[+ \text {pers },+ \text { num },+ \text { gen }]} \ldots \mathrm{DP}_{[+ \text {case }]} \ldots\right]$

As a consequence, the unitary probe can value case on the DP in (43a) and the split probe can achieve the same goal in (43b): first the features of $\mathrm{v}$ (inexhaustively) match those of the Goal and get checked on the Probe, in accordance with Principle Maximize.

${ }^{27}$ Witkoś $(2004,2007)$ rejects the following assumption, Chomsky (1999:4): "Structural case is not the feature of the Probes $(T, v)$ but it deletes under agreement if the Probe is appropriate, $[\varphi]$ complete. Case itself is not matched but deletes under matching of $[+\varphi]$ features."

${ }^{28}$ An empirical motivation for introducing an additional feature in the case-agreement relation, here called [+case], rather than lumping two defective Probes into a complete one, comes from examples like the one below:

(i) John is believed $[\mathrm{TP} t \mathrm{~T}[+$ pers $]$ to have been mugged[ $[-\varphi] \mathrm{t}]$.

Here, the combination of two defective Probes: the participle with number and gender features and the embedded Tense with the person feature may not result in a successful case-agreement relation. The case of the embedded object is valued by the matrix complete Probe T. The feature composition suggested above also prevents licensing of GoN in a passive construction in Polish. 
The case feature on the Goal DP is not checked, as $v$ is still incomplete. The features on $\mathrm{v}$ are checked but disappear only at the level of the strong phase. Hence they are still visible when Polarity $(\mathrm{Pol})$ has been merged and together with the feature [+case] on Pol they can still affect the goal. Note that this account follows the idea that checked formal features are still alive and accessible until the point of Transfer at the end of the strong phase. ${ }^{29}$ Naturally, Witkoś $(2004,2007)$ predicts that $\mathrm{v}$ and Pol can constitute a split probe only if they are both placed within the same derivational phase. ${ }^{30}$ In sum, the checking of the case of the object in Polish involves an amalgamated Probe consisting of two heads that complement each other; when Pol is set to the positive value, the case on the object comes out as Accusative, when Pol is Neg, it values the case as Genitive. Thus, as Witkoś (2004) concludes:

(45) Assignment of structural case can be contingent on a single functional head or can be spread between two functional heads.

Polish and English seem to make use of feature spread in the case of two distinct structural cases. In English the assignment of Nominative is contingent on feature spread between $\mathrm{C}$ and $\mathrm{T}$, while in Polish it is carried out by $\mathrm{T}$ (if our radical view of the AntiSubject Condition is correct). In English the assignment of Accusative is left to the single Probe v, whereas in Polish the assignment of the structural Accusative/Genitive is contingent on feature spread between two heads: Polarity and v.

\section{Conclusion}

This brief paper provides an assessment and a critical review of the main ideas proposed in Chomsky (2005). We have tried to focus on both the positive and the not-sopositive (in our modest view) consequences of the new proposal concerning mainly 'feature spread' and the idea that only phase heads act as Probes. We have shown in section seven that 'feature spread' may be independently required in syntax. The new account opens up a way to a principled explanation of the Subject Condition and the antiSubject Condition but at the same time it requires a new explanation of the That-trace Effect and several related problems. Time will show how influential and seminal this new set of Chomsky's ideas will prove to be.

\footnotetext{
${ }^{29}$ Pesetsky and Torrego (2001) claim that features "marked for deletion" are still visible and accessible to the computation until the completion of the CP layer or even beyond.

${ }^{30}$ The idea that there could be "split" Probes or "half" Probes is not new and was explicitly considered at the previous stage of the minimalist enterprise. Chomsky (1995) observed that unaccusatives and participles showed agreement features and, judging from the fact that they were supposed to include a "bare" $V$ rather than the combination of $\mathrm{v}-\mathrm{V}(\mathrm{VB})$, he suggested that $\mathrm{V}$ could be the locus of agreement features, while $\mathrm{v}$ could be the locus of the case feature. The notion of a "split" Probe is also inherent in Agr-based minimalism: for example in the feature checking of the subject with Agr and $\mathrm{T}$ in place but in the context of caseagreement under c-command rather than Attract $\mathrm{F}$.
} 


\section{REFERENCES}

Abraham, W., S. Epstein, H. Kitahara and J.W. Zwart (eds.).1996. Minimal ideas. Amsterdam: John Benjamins.

Boeckx, C. and N. Hornstein. 2004. "Movement under control”. Linguistic Inquiry 35. 431-452.

Bondaruk, A. 2004. PRO and Control. Lublin: Katolicki Uniwersytet Lubelski.

Boškovič, Z. 2002. "On multiple Wh-fronting”. Linguistic Inquiry 33. 351-383.

Cegłowski, P. 2006. Why Move? The analysis of the representational and derivational approaches to English syntax. [Unpublished PhD dissertation, Adam Mickiewicz Unviersity, Poznań.]

Chomsky, N. 1995. The minimalist program. Cambridge, MA: MIT Press.

Chomsky, N. 1998/2000. "Minimalist inquiries: The framework". In Martin, R., D. Michaels and J. Uriagereka (eds.), Step by step: Essays in honour of Howard Lasnik. Cambridge, MA: MIT Press. 89-156.

Chomsky, N. 1999. "Derivation by Phase". MIT Occasional Papers in Linguistics 18.

Chomsky, N. 2001. Beyond explanatory adequacy. [Manuscript, MIT, Cambridge, MA.]

Chomsky, N. 2005.On phases. [Manuscript, MIT, Cambridge, MA.]

Chomsky, N. 2006. Approaching UG from below. [Manuscript, MIT, Cambridge, MA.]

Dziwirek, K. 1998. "Reduced constructions in Universal Grammar: Evidence from the Polish object control construction". Natural Language and Linguistic Theory 16. 53-99.

Epstein, S.D. and N. Hornstein (eds.). 1999. Working minimalism. Cambridge, MA: MIT Press. Hendrick, R. (ed.). 2003. Minimalist syntax. Oxford: Blackwell.

Hiraiwa, K. 2001. "Multiple Agree and the Defective Intervention Constraint in Japanese". MIT Working Papres in Linguistics 40. 67-80.

Hornstein, N. 2000. Move! A minimalist theory of construal. Cambridge, MA: Blackwell.

Hornstein, N. 2003. “On Control”. In Hendrick, R. (ed.), Minimalist syntax. Oxford: Blackwell. 6-81. Kenstowicz, M. (ed.). 2001. Ken Hale: A life in language. Cambridge, MA: MIT Press.

Koizumi, M. 1995. Phrase structure in minimalist syntax. [Unpublished PhD dissertation, MIT, Cambridge, MA.]

Koopman, H. 1983. "ECP effects in main clauses". Linguistic Inquiry 14. 346-350.

Landau, I. 2000. Elements of control. Structure and meaning in infinitival constructions. Dordrecht: Kluwer.

Landau, I. 2004. "The scale of finiteness and the calculus of Control". Natural Language and Linguistic Theory 22. 811-877.

Landau, I. 2007. "Two routes of control: Evidence from case transmission in Russian". [Manuscript, Ben-Gurion University of the Negev, Beersheba.]

Lasnik, H. 1999. Minimalist analysis. Oxford: Blackwell.

Lasnik, H. and M. Saito. 1984. "On the nature of proper government". Linguistic Inquiry 15. 235-289.

Lubańska, M. 2005. Focus on Wh-questions. Franfurt am Main: Peter Lang.

Martin, R., D. Michaels and J. Uriagereka (eds.). 2000. Step by step: Essays in honour of Howard Lasnik. Cambridge, MA: MIT Press.

Pesetsky, D. and E. Torrego. 2000. "T-to-C Movement: Causes and Consequences". In Kenstowicz, M. (ed.). 355-426.

Przepiórkowski, A. 1999. Case assignment and the complement/adjunct dichlotomy. A nonconfigurational constraint-based approach. [Unpublished $\mathrm{PhD}$ dissertation, University of Tübingen.]

Przepiórkowski, A. 2004. "O wartości przypadka podmiotów liczebnikowych" [On the grammatical case of numeral subjects]. Biuletyn Polskiego Towarzystwa Językoznawczego 60. $133-144$. 
Richards, N. 2001. Move in language; interactions and architectures. Oxford: Oxford University Press.

Rizzi, L. 1990. Relativised minimality. Cambridge, MA: MIT Press.

Tajsner, P. 1990. Case marking in English and Polish: A government and binding study. [Unpublished PhD dissertation, Adam Mickiewicz University, Poznań.]

Thrainsson, H. 1996. "On the (non)universality of functional projections". In Abraham, W., S. Epstein, H. Kitahara and J.W. Zwart, (eds.). 253-281.

Thrainsson, H. 2003. "Syntactic variation, historical development and minimalism". In Hendrick, R. (ed.). 152-191.

Uriagereka, J. 1999. "Multiple spell-out”. In Epstein, S. D. and N. Hornstein (eds.). 251-82.

Willim, E. 1990. "On case marking in Polish". Papers and Studies in Contrastive Linguistics 25. 204-220.

Witkoś, J. 2004. "Some notes on single cycle syntax and Genitive of Negation". Generative Linguistics in Poland: Proceedings of the GliP-5 Conference. Instytut Podstaw Informatyki Polskiej Akademii Nauk: Warszawa.

Witkoś, J. 2007. "Genitive of Negation in Polish and single-cycle derivations". To appear in Journal of Slavic Linguistics. 